\title{
Globalização e divisão sexual do trabalho*
}

\author{
Helena Hirata**
}

\begin{abstract}
Resumo
A partir de uma discussão sobre os contornos e os limites da noção de "globalização", o artigo analisa as profundas transformações que ocorrem no(s) mundo(s) do trabalho nos anos noventa, detendo-se particularmente em três questões: as conseqüências da globalização sobre a divisão sexual do trabalho; as novas características do emprego feminino na crise; o debate francês sobre as alternativas institucionais e jurídicas, que se referem ao debate anterior sobre o "fim do trabalho" ou a "centralidade do trabalho"; em conclusão, serão apresentadas as alternativas propostas pelos movimentos sociais à crise do emprego e ao desenvolvimento da precariedade.
\end{abstract}

Palavras-chave: Globalização, Gênero, Condições de Trabalho, Direito Social, Movimentos Sociais.

\footnotetext{
" Recebido para publicação em dezembro de 2001.

** Socióloga, núcleo de pesquisa GERS (Genre et rapports sociaux), Centre National de la Recherche Scientifique, França.
} 
Globalização e divisão sexual do trabalho

Globalization and the Sexual Division of Labour

\begin{abstract}
The discussion about the caracteristics and the limits of the notion of "globalization" will conduct us to the analysis of the deep transformations of the world(s) of work during the nineties. Three issues interest us: first, the effects of globalization on the sexual division of labour; second, the new trends of female employment in the crisis; third, the French debate about the institutional and juridical alternatives related to the previous discussion about the "end of work" or the "centrality of work"; in conclusion, we will refer to the alternatives coming from the social mouvements against the employment crisis and the development of precariousness.
\end{abstract}

Key words: Globalization, Gender, Working Conditions, Labour Law, Social Mouvements. 
A reflexão sobre a globalização é inseparável de uma desconstrução dessa noção, que utilizaremos como categoria analítica, ao mesmo tempo em que criticamos seu uso neoliberal enquanto modelo normativo (consagração da ordem estabelecida, fatalismo de um movimento necessário e inelutável). ${ }^{1}$ A interdependência crescente dos mercados nacionais com vistas à constituição de um mercado mundial unificado, a despeito de suas forças homogeneizantes, não suprime a diversidade, mas aguça a heterogeneidade das situações de trabalho, de emprego e de atividade das mulheres e dos homens, do Sul e do Norte. "Inclusão" ou "exclusão" podem ser considerados termos para designar a estruturação de zonas desenvolvidas e de zonas excluídas do desenvolvimento (o caso de uma grande parte da África, por exemplo). Os anos noventa foram o palco de mudanças significativas no contexto internacional, que levaram ao desenvolvimento crescente da precariedade e da informalidade, no(s) mundo(s) do trabalho e da produção, tanto nos países do Norte como nos do Sul. Três questões relativas a tais mudanças serão abordadas nesse texto. Em primeiro lugar, as conseqüências da globalização sobre o emprego e a divisão sexual do trabalho; em segundo lugar, as transformações no trabalho $e$ as características do emprego feminino na crise; em terceiro lugar, o debate francês sobre as alternativas - institucionais, jurídicas, e aquelas propostas pelos movimentos sociais - a esta crise do emprego e ao desenvolvimento do trabalho flexível e precário.

\footnotetext{
${ }^{1}$ Para a apresentação crítica dessa noção, cf. HIRATA, Helena; LE DOARE, Helene. (coords.) Les paradoxes de la mondialisation. Cahiers du Gedisst, n ${ }^{\circ}$, 1998, pp.5-34.
} 
Globalização e divisão sexual do trabalho

\title{
1. Globalização, trabalho e gênero
}

\subsection{Contornos e limites da noção}

A definição capitalista de globalização, segundo um diretor de um dos maiores grupos europeus, citado por François Chesnais, restitui a noção de um movimento sem freios do capital em escala mundial. Segundo este empresário, a globalização é

\begin{abstract}
a liberdade para o seu grupo de se implantar onde ele quiser, o tempo que ele quiser, para produzir o que ele quiser, comprando e vendendo onde ele quiser, e tendo que suportar o menor número de obrigações possíveis em matéria de direito do trabalho e de convenções sociais. ${ }^{2}$
\end{abstract}

Os economistas críticos têm em comum na sua definição do fenômeno a idéia da ruptura de limites e fronteiras: "interdependência crescente de todos os mercados nacionais em vistas à constituição de um mercado mundial unificado"3; "processo que conduz um número sempre maior de agentes econômicos a situar seus projetos $e$ a realizar suas operações numa perspectiva e numa escala mundial". "Trata-se, como afirma este último, de tendências históricas da internacionalização do capital, mas o que é novo neste processo é "a intensidade dos fluxos, a variedade dos produtos, o número de agentes econômicos implicados nesse movimento". ${ }^{5}$ Ao menos três dimensões que contribuem para a novidade do processo devem ser assinaladas. Em primeiro lugar, ele é impulsionado por

2 CHESNAIS, François. La mondialisation du capital. Nouvelle édition augmentée, Paris, Syros, 1997, p.22.

3 LIPIETZ, Alain. La société en sablier. Le partage du travail contre la déchirure sociale. Paris, La découverte, 1996, p.43.

4 Petit, Pascal. Dictionnaire de Sociologie, Le Robert, Supplément, 2000.

5 ID., IB. 
políticas governamentais neoliberais com conseqüências no plano da liberalização das trocas comerciais, a desregulamentação, a abertura dos mercados e novas lógicas de desenvolvimento das firmas multinacionais, tendo como corolários as privatizações, o desenvolvimento da sub-contratação e da externalização da produção; em segundo lugar, o desenvolvimento acelerado das tecnologias de informação e de comunicação $e$ a expansão das redes, tornando possível a circulação imediata de informações e de dados de toda ordem e a financiarização das economias; em terceiro lugar, o novo papel desempenhado pelos organismos internacionais, cujo papel regulador se efetua paralelamente, $e$ nem sempre em harmonia com a regulação pelos Estados-Nação $e$ pelas firmas internacionais. Este novo quadro econômico e financeiro tem conseqüências diferenciadas segundo as regiões do globo, e sobre a divisão sexual do emprego, do trabalho profissional $e$ domestico $-e$ da atividade dos homens $e$ das mulheres.

\subsection{Emprego e divisão sexual do trabalho}

Os efeitos da globalização, complexas e contraditórias, afetaram desigualmente o emprego masculino e feminino nos anos noventa. Se o emprego masculino regrediu ou se estagnou, a liberalização do comércio e a intensificação da concorrência internacional tiveram por conseqüência um aumento do emprego e do trabalho remunerado das mulheres ao nível mundial, com a exceção da África sub-sahariana. Notou-se um crescimento da participação das mulheres no mercado de trabalho, tanto nas áreas formais quanto nas informais da vida econômica, assim como no setor de serviços. Contudo, essa participação se traduz principalmente em empregos precários e vulneráveis, como tem sido o caso na Ásia, Europa e América Latina. As pesquisas realizadas por economistas feministas indicam claramente essa 
Globalização e divisão sexual do trabalho

tendência. ${ }^{6}$ Trata-se de um dos paradoxos da globalização, este aumento do emprego remunerado acompanhado pela sua precarização e vulnerabilidade crescentes. Pode-se dizer que as desigualdades de salários, de condições de trabalho e de saúde não diminuíram, e que a divisão do trabalho doméstico não se modificou substancialmente, a despeito de um maior envolvimento nas responsabilidades profissionais por parte das mulheres. Assim, Ruth Pearson ${ }^{7}$ demonstra que a globalização representa novas oportunidades, mas também novos riscos para as mulheres trabalhadoras. Suas pesquisas mostram que as desigualdades sociais nas relações de trabalho e saúde parecem ter piorado sob o impacto das políticas de flexibilização.

As conseqüências dessa evolução da atividade feminina são múltiplas, mas pode-se dizer que uma das mais importantes consiste no fato de que este modelo de trabalho precário, vulnerável e flexível pode constituir um modelo que prefigura um regime por vir de assalariamento masculino e feminino. Dito de outra maneira, as trabalhadoras podem ser vistas como cobaias para o desmantelamento das normas de emprego predominantes até então. Um cenário possível neste contexto seria a extensão ou a generalização deste modelo a toda a população ativa, inclusive a masculina. As mulheres podem ser mais facilmente "cobaias" de experimentações sociais porque são menos protegidas, tanto pela legislação do trabalho quanto pelas organizações sindicais, e são mais vulneráveis. Embora o cenário mais provável seja o de uma dupla segmentação, com a constituição de dois segmentos do

${ }^{6}$ BenERIA, Lourdes; Floro, Maria; Grown, Caren; MacDonald, Martha. Globalization and Gender, A Special Issue on Globalization. Feminist Economics, vol. 6, number 3, november 2000, pp.vii-xviii; GROwN, Caren; Elson, Diane; CAGATAY, Nilufer. Gender inequalities, macroeconomics and global trade and finance. World Development, vol. 28, issue 7, n especial, 2000.

7 PEARSON, Ruth. Gender perspectives on health and safety in information processing: learning from international experience. Women Encounter Technology. Changing Patterns of Employment in the Third World. London/NY/Routledge/UNU Press, 1995, pp.278-302. 
emprego masculino e dois segmentos do emprego feminino, um estabilizado, outro precarizado, a força dissuasiva e de pressão sobre salários, condições de trabalho e de negociação dos trabalhadores de ambos os sexos parece evidente.

Nos países do Norte, este modelo se encarnou na figura do trabalho em tempo parcial. Ocupado majoritariamente, de $80 \%$ (França) a mais de 95\% (Japão) por mulheres, e significando um salário parcial, ele agrava as disparidades existentes na repartição do trabalho doméstico no interior do casal. Nos países do Sul, ele se encarnou na figura do trabalho informal, sem nenhuma proteção social. Também nela, as mulheres estão maciçamente representadas. As empregadas domésticas e as diaristas, em primeira posição entre mulheres trabalhadoras naqueles países, exercem esse trabalho majoritariamente sem vínculo empregatício formal. Nos dois casos, tempo parcial e trabalho informal, trata-se - sobretudo no que diz respeito aos empregos fora do setor público e particularmente no comércio e nos serviços - de trabalhos freqüentemente instáveis, mal remunerados, com uma possibilidade quase inexistente de formação, de promoção e de carreira, e com direitos sociais limitados ou inexistentes...

Um dos resultados destes processos consiste na exacerbação das desigualdades sociais, mas a atomização dos trabalhadores homens e mulheres com as modalidades de empregos precários ou trabalhando isolados (trabalho a domicílio, teletrabalho) não impede e pode mesmo constituir, paradoxalmente, o quadro para a emergência de novas atrizes $e$ atores coletivos: as lutas antiglobalização ou alter (por uma outra)-globalização.

\section{Globalização e transformações do trabalho}

As mudanças tecnológicas e organizacionais tiveram impactos complexos e contraditórios sobre o trabalho. Trata-se, para nós, de uma "transformação paradoxal do trabalho". 
Globalização e divisão sexual do trabalho

\subsection{Envolvimento do trabalhador e intensificação do trabalho}

O contexto atual está profundamente marcado por uma transformação dupla - e paradoxal - do trabalho, caracterizado, por um lado, pela estabilidade requerida pelos "novos modelos de produção" que apela ao forte envolvimento do trabalhador, e, de outro, pela insegurança no emprego devida ao desenvolvimento da flexibilidade do trabalho e ao aumento do desemprego. Essa transformação requer uma análise simultânea do conteúdo da atividade e das formas do emprego; da organização do trabalho ao nível da empresa e dos processos de segmentação ao nível do mercado de trabalho. Há complementaridade entre, de um lado, a inovação tecnológica $e$, de outro, mudanças no status do emprego. Os vínculos de emprego se tornam cada vez mais precários com o aumento do desemprego de longo prazo, de formas ditas "atípicas" de emprego e da flexibilidade no uso da força de trabalho.

Entretanto, esse paradoxo é menos forte do que parece à primeira vista, porque o processo de instabilidade termina por alcançar o centro da organização do trabalho e não só o status do emprego. Os levantamentos franceses (Ministério do Trabalho, 1984, 1991, 1998) e europeus (Eurostat) sobre condições de trabalho mostram uma deterioração real dessas condições nos últimos quinze anos com a intensificação do trabalho $e$ o aumento da dependência em relação à hierarquia. ${ }^{8}$ De fato, o aumento da autonomia e da iniciativa do trabalhador, com a redução de níveis hierárquicos, podem coexistir com a intensificação do trabalho, $e$ pode mesmo contribuir para ela pelo processo de autointensificação. Resultados recentes de pesquisa de Serge Paugam ${ }^{9}$

8 Gollac, Michel; VOLKOFF, Serge. Citius, altius, fortius. L'intensification du travail. Actes de la recherche en sciences sociales, ${ }^{\circ} 114$, septembre 1996 , pp.54-67; e Les conditions de travail. Paris, La Découverte, Repères, 2000, 121p.

9 Paugam, Serge. Le salarié de la précarité. Paris, PUF, 2000, 437p. 
sublinham a pressão gerada pela obrigação de autogerenciamento dos trabalhadores, das exigências contraditórias entre as práticas do just in time em termos de quantidade $e$ a simultânea pesquisa da qualidade. A literatura especializada dá ênfase à importância dos impactos dessas ordens contraditórias sobre a saúde mental e física. ${ }^{10}$

\subsection{Crise do emprego e tendências atuais de transformação do trabalho feminino}

Essa "transformação paradoxal do trabalho" caracteriza uma situação que implica em diminuição tendencial de empregos estáveis e precariedade de uma proporção significativa da população ativa. Ela termina por configurar a situação de crise do paradigma do emprego estável e protegido. Na França, em 1998, uma de cada 11 pessoas empregadas tinha um status precário ${ }^{11}$; em 2000, apenas $57 \%$ de todos os empregos na França eram estáveis. A flexibilidade no volume dos empregos e no tempo de trabalho é garantida basicamente pelas mulheres nos padrões de trabalho presentemente adotados ao nível internacional.

Duas tendências recentes da evolução do trabalho feminino podem ser apontadas: (1) a bi-polarização do trabalho assalariado feminino, ao lado de uma maior diversificação de tarefas $e$ funções e de um crescimento da minoria significativa de mulheres pertencentes à categoria estatística "profissões executivas e intelectuais"; (2) o desenvolvimento do setor de serviços e o impacto de novas profissões também polarizadas em termos de relações de gênero, classe e raça/etnia.

\footnotetext{
${ }^{10} \mathrm{cf}$. ApPay, Béatrice; ThÉBAud-Mony, Annie. (sous la dir. de) Précarisation sociale, travail et santé. Paris, IRESCO/CNRS, 1997; GOLLAC, M.; VOLKOFF, S. Les conditions de travail. Op. cit.

${ }^{11}$ BLOCH, Laurence, ESTRADE, Marc-Antoine. Les formes particulières d'emploi en France: un marchepied vers les emplois stables? France, portrait social, 19981999. Paris, INSEE, 1998.
} 
Globalização e divisão sexual do trabalho

A atividade feminina continua concentrada em setores como serviços pessoais, saúde e educação. Contudo, a tendência a uma diversificação das funções mostra hoje um quadro de bipolarização: num extremo, profissionais altamente qualificadas, com salários relativamente bons no conjunto da mão-de-obra feminina (engenheiras, arquitetas, médicas, professoras, gerentes, advogadas, magistradas, juizas, etc.), e, no outro extremo, trabalhadoras ditas de "baixa qualificação", com baixos salários e tarefas sem reconhecimento nem valorização social. Essa bipolarização não surge apenas nos países europeus desenvolvidos ${ }^{12}$, mas também em países semi-industrializados como o Brasil. ${ }^{13}$ Kergoat mostra um forte crescimento da categoria "profissões executivas e intelectuais superiores", que passaram de 440.276 em 1982 para 895.408 em 1994. ${ }^{14}$ Battagliola dá para 1998 a cifra de 1.027.445; ou a taxa total de atividade feminina como 10.053.694 para o mesmo ano. Em outras palavras, pouco mais de $10 \%$ do trabalho feminino pertence agora à categoria das "profissões executivas e intelectuais superiores". ${ }^{15}$ Entretanto, a taxa de feminização dessas profissões passou na França de $24 \%$ em 1982 para 34\% em 1998.

No extremo inferior, assistimos ao crescimento do trabalho precário, em tempo parcial e temporário como o $\mathrm{CDD}$ (contrat à durée déterminée, contrato por tempo fixo de emprego), o CES (contrat emploi solidarité, contrato de emprego solidariedade, trabalho de meio-período subsidiado pelo governo), etc. Empregos precários - mal pagos e sem perspectiva de carreira. A

\footnotetext{
${ }^{12}$ KeRgoht, Danièle. La division du travail entre les sexes. In: KeRGOAT, J. et alii (sous la direction de.) Le monde du travail. Paris, La découverte, 1998, pp.319- 327.

${ }^{13}$ BRUSCHINI, Cristina. Gênero e trabalho no Brasil: novas conquistas ou persistência da discriminação? In: BALTAR DA ROCHA, M.I. (org.) Trabalho e gênero. Mudanças, permanências e desafios. São Paulo, Editora 34, 2000, 383p.

${ }^{14}$ KeRGOAT, D. La division du travail entre les sexes. Op. cit., p.322.

${ }^{15} \mathrm{cf}$. Battagliola, Françoise. Histoire $d u$ travail des femmes. Paris, La découverte, 2000, p.95.
} 
bi-polarização cria dois grupos de mulheres com perfis sociais $e$ econômicos opostos. Kergoat teoriza o antagonismo político potencial entre esses dois grupos. ${ }^{16}$ Uma das questões controversas é o fato de que um dos grupos usa os serviços do outro para ascender na escala profissional e ter uma carreira.

O desenvolvimento do emprego em serviços está, assim, estreitamente ligado a esse movimento e às crises econômicas $e$ recessão que levam mulheres inativas sem qualificações reconhecidas a entrarem no mercado de trabalho. A demissão no setor industrial é hoje na França compensada pela criação de empregos nos serviços, e na conjuntura de fins de 2001, especialmente para ajudar na transição para o "euro". ${ }^{17}$ No entanto, no setor de serviços a bi-polarização também é muito forte: se houve crescimento no número de mulheres gerentes nas divisões financeiras do setor de bancos e seguros, o "emprego de serviços", o chamado "serviço pessoal" (trabalho doméstico remunerado, guarda de idosos e crianças, etc.), também cresceu significativamente durante toda a década de 90 na Europa ${ }^{18}$, nos Estados Unidos ${ }^{19}$ e no Brasil. ${ }^{20}$ A multiplicação desse tipo de emprego em serviços reforça a "heterogeneidade" do setor terciário, em virtude da emergência de novas profissões femininas altamente qualificadas e proporcionalmente bem remuneradas. Embora documentos oficiais franceses sublinhem a importância

\footnotetext{
${ }^{16}$ KeRGOAT, D. La division du travail entre les sexes. Op. cit., pp.322-323.

${ }^{17}$ Le Monde, 11/9/2001, p.21.

${ }^{18}$ Fougeyrollas-SchWeBel, Dominique. De la réclusion au cloisonnement. Travail domestique et salariat. In: Defalvard, H.; GuIENNE, V. (sous la dir. de) Le partage du travail. Bilan et perspectives. Paris, Desclée de Brouwer, 1998, pp.157-168.

${ }^{19}$ MiLKMAN, Ruth et alii. A macrossociologia do trabalho doméstico remunerado. Revista Latinoamericana de Estudios del Trabajo, ano 4, n 7, 1998, pp.143167.

${ }^{20}$ BRUSCHINI, Cristina. Gênero e trabalho no Brasil... Op. cit.
} 
Globalização e divisão sexual do trabalho

"desses empregos potenciais" de serviços pessoais ${ }^{21}$ os efeitos perversos desses serviços são claros: eles diminuem o status já precário e sub-valorizado desse tipo de emprego, geralmente associado com a força de trabalho feminina.

Em oposição a essas tendências recentes no trabalho profissional feminino, as mudanças no trabalho doméstico são menores e muito mais lentas. Se o forte desenvolvimento das tecnologias domésticas tendeu a facilitar essas tarefas, a divisão sexual do trabalho doméstico $e$ a atribuição deste último às mulheres, em realidade, continuou intacta. A relação entre o trabalho doméstico e a afetividade parece estar no centro dessa permanência. $^{22}$

\section{O debate francês sobre as alternativas face às mudanças nas normas de emprego}

A exigência de novas regulações e de alternativas globais emerge face a um contexto definido por Castel como aquele em que "a diversidade e a descontinuidade das formas de emprego estão superando o paradigma do emprego homogêneo $e$ estável". ${ }^{23}$ De que forma se opor à tendência atual de precarização $e$ de instabilização crescentes $e$ de riscos de exclusão das categorias mais vulneráveis da população? Como enfrentar a crise econômica e o desemprego de massa que se desenvolveram durante os anos noventa? A discussão na França segue duas linhas principais: a que parte da distinção entre emprego, trabalho e atividade, e propõe uma "recodificação da relação de emprego", e a que afirma a exigência de um trabalho "decente" ou

${ }^{21}$ Cette, G. et alii. Emplois de proximité. Rapport au Conseil d'Analyse Economique. Paris, La Documentation Française, 1998, p.7.

${ }^{22}$ Cf. HiRATA, Helena. Travail et affects. De la servitude volontaire et du consentement. Communication au Journée du GDR-MAGE, Paris, le 8 juin. Documents de travail, n 5, MAGE/IRESCO, 2001.

${ }^{23}$ CASTEL, Robert. Les métamorphoses de la question sociale. Une chronique du salariat. Paris, Fayard, 1995, p.401. 
"conveniente" como norma alternativa face à crise atual do emprego.

\section{Alternativas entre emprego, trabalho $e$ atividade}

A distinção entre emprego, trabalho e atividade vem sendo feita desde o início dos anos oitenta pelas estudiosas do trabalho feminino como Kergoat ou Maruani. ${ }^{24}$ Tal distinção permitia indicar, por exemplo, que a relação positiva ao emprego, proporcionando um rendimento, pode se aliar, no caso das mulheres, a uma relação negativa ao trabalho repetitivo, monótono e penoso; essa distinção permitia também indicar que a atividade feminina poderia ser detectada de maneira quase que onipresente na sociedade, a despeito da falta de emprego (falta de proteção social, de contrato de trabalho, de salário) ou de um trabalho visível, reconhecido como tal através do estabelecimento de condições precisas de seu exercício e de uma remuneração fixa.

A distinção, bem mais tardia, entre trabalho, emprego $e$ atividade, efetuada por autores como Méda, Fouquet e Coutrot, aparece no contexto do debate sobre a "mutação radical da relação de emprego" 25 , mudança nas normas de emprego e desestabilização da relação salarial.

Esse debate desenboca, entre os especialistas do direito social ou do trabalho, na proposição de remodelar o quadro jurídico do contrato de trabalho, para evitar a insegurança na obtenção da renda e garantir sua continuidade. A idéia destes juristas é a de incluir no contrato de trabalho situações diferentes

${ }^{24}$ Kergoat, Danièle. Les ouvrières. Paris, Sycomore, 1982; MARUANI, Margaret. L'emploi féminin à l'ombre du chômage. Actes de la recherche en sciences sociales, $\mathrm{n}^{\circ} 115$, décembre 1996, pp.48-57.

${ }^{25}$ MÉDA, Dominique. Travail, emploi, activité: de quoi parle-t-on? Données sociales, 1997, p.104; FoUQUET, Annie. Travail, emploi et activité. La lettre, Centre d'Etudes de l'Emploi, $n^{\circ}$ 52, avril 1998; Coutrot, Thomas. Critique de l'organisation du travail. Paris, La Découverte, Repères, 1999, 121p. 
Globalização e divisão sexual do trabalho

da situação de emprego estável, tais como as de trabalho precário e descontínuo (trabalho por tempo determinado, temporário, sazonal, etc.), desemprego, formação, etc. Elas poderiam ser remuneradas por um pool de empregadores, pelo Estado, mas também por "associações, coletividades e organismos de formação ao nível dos ramos, das regiões ou dos territórios". ${ }^{26}$

Tais proposições, que vão no sentido de uma "recodificação da relação de emprego" ${ }^{27}$, reconhecem, assim, a emergência e a multiplicação de novas figuras de assalariados $e$ assumem múltiplas formas: as mais conhecidas são a do "contrato de atividade" 28 e a do "estado profissional", com droits de tirage sociaux (direito do trabalhador a optar por diferentes situações ao longo do tempo, a "tirar" tempo para si com vistas à formação profissional, a um período de benevolato, etc.). ${ }^{29}$ Pode-se afirmar que esta ultima proposição é a mais ampla e fornece uma alternativa global, sob o plano jurídico, às incertezas relacionadas ao mercado de trabalho, ao emprego, ao posto de trabalho e à renda.

Supiot tenta formular, ao nível jurídico, uma alternativa às descontinuidades do emprego devidas à flexibilidade do trabalho, com passagens freqüentes do emprego ao desemprego, ao trabalho precário, à inatividade, etc..$^{30}$ Ele afirma a necessidade de assegurar uma certa continuidade às relações de trabalho $e$ ao "estado profissional", a despeito da descontinuidade das praticas laborais, e inspira-se na experiência italiana das "Cassa Integrazioni". ${ }^{31}$ Segundo Supiot, essa experiência indica como

${ }^{26}$ Coutrot, T. Critique de l'organisation du travail. Op. cit., pp.100-101.

${ }^{27}$ BÉLANGER, Jacques; THUDEROZ, Christian. La recodification de la relation d'emploi. Revue Française de Sociologie, XXXIX-3, juillet-septembre 1998.

${ }^{28}$ BoIssonNAT, Jean. (coord.) Le travail dans vingt ans. Paris, Odile Jacob, 1996.

${ }^{29}$ SuPIOT, Alain. (sous la dir. de) Au-delà de l'emploi. Transformations du travail et devenir du droit du travail en Europe. Rapport pour la Comission européenne, Paris, Flammarion, 1999.

${ }^{30}$ ID., IB., p.70.

${ }^{31}$ ID., IB., p.70-71. 
financiar períodos de trabalho, férias, formação profissional, etc. através da cooperação entre empresas, fundos públicos, etc. Ele critica em dois pontos o conceito de "contrato de atividade" de Boissonat. Em primeiro lugar, o termo "contrato" não seria pertinente, na medida em que o "estado profissional" tenta integrar situações e períodos da existência fora de toda troca contratual dentro do mercado de trabalho; em segundo lugar, o termo "atividade" não seria pertinente do ponto de vista jurídico ${ }^{32}$, na medida em que tal termo é demasiado amplo e inseparável da vida. Os direitos sociais relacionados à atividade, sendo direitos universais, a referência à atividade não configuraria uma base para direitos específicos. Para dar fundamento à tese de um "estado profissional" contra a flexibilidade do capital e face às transformações do trabalho, Supiot apresenta três hipóteses principais $^{33}$

1) estratégias de resistência, que consiste na defesa por parte dos sindicatos e dos juristas, de uma situação de status salarial estável, para fazer face a um empregador único e desfrutar, assim, de um contrato de trabalho por tempo indeterminado;

2) estratégias de adaptação, que procuram preservar o status salarial estável, mas tentam assegurar simultaneamente um mínimo de proteção social para fazer face à flexibilidade;

3) estratégias de adaptação ativa, onde se procura uma reinstitucionalização das relações salariais, com a fixação de novas regras e de um espaço de negociação dessas regras. Essa estratégia ofensiva permitiria, enfim, conciliar segurança $e$ liberdade, com o exercício do droit de tirage (direito do trabalhador a optar por situações diferentes ao longo do tempo). As primeiras duas estratégias mencionadas partem do reconhecimento e da aceitação de uma segmentação entre duas categorias de trabalhadores segundo o seu grau de estabilidade;

32 ID., IB., pp.87-88.

${ }^{33}$ ID., IB., pp.84-85. 
Globalização e divisão sexual do trabalho

por essa razão, Supiot considera a terceira hipótese como sendo a mais interessante a ser desenvolvida.

\subsection{O "fim do trabalho" e o futuro do emprego}

Esse segundo debate, sobre o emprego desejável, "conveniente", que se superpõe ao primeiro, tomou múltiplas formas:

- a retomada da conceitualização da Organização Internacional do Trabalho (OIT) de um trabalho "decente", conceito oposto ao de "desqualificação" ${ }^{34}$ Assim, Jacques Freyssinet ${ }^{35}$ desenvolve o conceito de "emprego conveniente", contra suas formas degradadas e precárias;

- o desenvolvimento de uma análise prospectiva sobre o futuro do trabalho. ${ }^{36}$ Pensar o fim do trabalho, enquanto "fim da organização dominante do trabalho sob a forma do emprego assalariado" aparece aqui como uma pré-condição para pensar os novos fundamentos requeridos para "manter a perenidade da relação (lien) social" ${ }^{37}$;

- a elaboração de alternativas sobre o tipo de trabalho desejável, no seio dos próprios movimentos sociais. Por exemplo, no movimento social das enfermeiras, que se organizaram no fim dos anos oitenta sob a forma de "coordenação" de trabalhadores sindicalizados e não sindicalizados, foi postulada a exigência de um trabalho com "valor de uso" e não apenas com "valor de

${ }^{34}$ PAUGAM, S. La disqualification sociale. Paris, PUF, 1991.

${ }^{35}$ FREYSSINET, Jacques. Plein emploi, droit au travail, emploi convenable. Revue de I'IRES, n 34, 2001, pp.27-58.

${ }^{36}$ CASTEL, R. Les métamorphoses de la question sociale... Op. cit.; e Centralité du travail et cohésion sociale. In: KERGOAT, J. et alii (sous la dir. de) Le monde du travail. Paris, La découverte, 1998.

${ }^{37}$ ID. Centralité du travail et cohésion sociale. Op. cit., p.51. 
troca" ${ }^{38}$; também no movimento dos desempregados, como o AC (Agir ensemble contre le chômage - Agir juntos contra $\mathrm{O}$ desemprego), a idéia de qualificar o emprego desejado não como "um emprego qualquer", mas como dotado de um "sentido", "interessante", dotado de "valor". Não se trata aqui de uma procura de uma situação de pleno emprego, de quantum de empregos, mas também de empregos de qualidade.

Enfim, a importância e o impacto da ação de outros movimentos sociais devem ser ressaltados. A Marcha Mundial das Mulheres e outros movimentos anti-globalização ${ }^{39}$ propõem alternativas contra a crise, a precariedade e a flexibilidade crescentes do trabalho. Pode-se incluir entre elas, no caso da França, a ação coletiva de 150 sindicatos, associações e grupos de mulheres organizados no Collectif National des Droits des Femmes (Coletivo Nacional dos Direitos das Mulheres) - CNDF, que participam de iniciativas contra o emprego em tempo parcial, o trabalho precário, as violências contra as mulheres.

Para além do debate sobre as alternativas institucionais $e$ jurídicas acima apresentado, os movimentos sociais continuam a conduzir ações significativas, desenvolvidas, sobretudo, a partir das grandes greves de 1995, a despeito da sindicalização decrescente no país, o que parece ser uma especificidade francesa.

${ }^{38}$ KERGOAT, Danièle. et alii. Les infirmières et leur coordination. Paris, Lamarre, 1992.

${ }^{39}$ Cf. SeOne, Jose; TAdDEI, Emilio. (compil.) Resistencias mundiales. De Seattle a Porto Alegre. Buenos Aires, CLACSO, 2001, 207p. 
Globalização e divisão sexual do trabalho

Fica por analisar o papel do Estado francês e das políticas públicas na configuração específica que assumem hoje esses movimentos sociais. ${ }^{40}$

\footnotetext{
${ }^{40}$ Os movimentos sociais, onde os secundaristas e os jovens das periferias das grandes cidades se destacam, contra a extrema-direita, a xenofobia e o racismo ocupam diariamente as ruas das cidades francesas desde o primeiro turno das eleições presidenciais de 21 de abril de 2002. Seus resultados colocaram os eleitores diante da alternativa inédita entre direita e extrema-direita. O desenvolvimento da mobilização social em tal contexto político é uma outra especificidade da situação política francesa. Ter que escolher entre um ladrão (o presidente em exercício Chirac) e um fascista (Le Pen) é um apanágio dos eleitores deste país: em países onde ambos os traços podem ser encontrados num mesmo indivíduo, o problema não apareceria com a mesma acuidade...
} 